\title{
A Escola de Educação Física da Universidade Federal do Rio Grande do Sul e a Internacionalização da Educação Superior
}

\author{
Alberto Reinaldo Reppold Filho* \\ Lisiane Torres e Cardoso** \\ Marco Aurélio Vaz***
}

\begin{abstract}
Resumo: Neste estudo, descrevemos o caminho seguido pela ESEF-UFRGS na direção da internacionalização da pesquisa e da graduação e destacamos alguns desafios para sua efetivação. A pesquisa tomou como referência depoimentos de docentes, documentos institucionais, registros de atividades de pesquisa e publicações científicas sobre a trajetória institucional. Os resultados indicaram que a ESEFUFRGS vem desenvolvendo iniciativas em direção à internacionalização da pesquisa e da graduação. As principais iniciativas foram mobilidade de estudantes e docentes, publicações em periódicos internacionais e participação em eventos com e sem apresentação de trabalhos. O maior desafio tem sido instalar uma cultura de internacionalização em que a relação com instituições de educação superior de outros países seja vista como qualificadora das atividades de ensino e pesquisa.
\end{abstract}

Palavras-chave: Educação Física. História. Educação Superior.

\section{INTRODUÇÃO}

Criada em 1940, a Escola de Educação Física (ESEF) da Universidade Federal do Rio Grande do Sul (UFRGS) é uma das instituições mais antigas do país a oferecer cursos de formação na área da Educação Física. Durante as primeiras três décadas de

\footnotetext{
*Professor da ESEF - UFRGS. Porto Alegre, RS, Brasil.

${ }^{* *}$ Professor da ESEF - UFRGS. Porto Alegre, RS, Brasil.

${ }^{* * *}$ Professor da ESEF - UFRGS. Porto Alegre, RS, Brasil.
} 
funcionamento, fez parte do Departamento Estadual de Educação Física do Rio Grande do Sul. Em 1969, por meio de um processo de federalização, foi integrada à Universidade Federal do Rio Grande do Sul.

Com o propósito de atender às demandas do sistema educacional, a ESEF vem, ao longo dos anos, dedicando especial atenção à preparação de professores de Educação Física para atuar nas redes pública e privada de ensino. A ESEF tem se dedicado também a formação de profissionais para atuar em contextos extraescolares, em especial naqueles que oferecem projetos e serviços nas áreas do esporte, do lazer e das atividades físicas relacionadas à saúde. Recentemente, a instituição passou a oferecer dois novos cursos de graduação: Fisioterapia e Dança. Na atualidade, são atendidos cerca de 1000 estudantes de graduação.

A ESEF tem uma longa tradição em pesquisa, que teve início nos anos de 1970 com a criação do Laboratório de Pesquisa do Exercício (LAPEX). Desde então, uma ampla variedade de estudos vem sendo desenvolvidos. Atualmente existem 17 grupos de pesquisa em funcionamento, que estudam a educação física, o esporte, o lazer, a dança e a atividade física a partir de diferentes disciplinas científicas.

No nível da pós-graduação, a ESEF oferece cursos de especialização (pós-graduação lato sensu) desde a década de 1970. $\mathrm{Na}$ atualidade, são atendidos anualmente cerca de 120 profissionais de diversas áreas, que buscam aprofundar estudos e qualificar sua formação. Em 1989, foi criado o Programa de Pós-Graduação em Ciências do Movimento Humano (PPGCMH), cujo objetivo principal é a produção do conhecimento e a formação de pessoal para as atividades de ensino, de pesquisa e de desenvolvimento tecnológico, no âmbito das Ciências do Movimento Humano. O PPGCMH atende 110 estudantes de mestrado e doutorado. Mais recentemente, a ESEF passou a oferecer estágios de pós-doutoramento para pesquisadores egressos da própria instituição e de instituições congêneres do país e do exterior. 
A ESEF tem uma forte conexão com a comunidade, oferecendo uma ampla variedade de projetos para públicos de diferentes idades. Semanalmente, centenas de pessoas participam dos projetos de extensão desenvolvidos pela instituição. Além disso, são realizadas muitas atividades científicas e de formação continuada, como cursos de curta duração, congressos, seminários e palestras, dirigidas tanto ao público especializado, como à população em geral.

Ao longo dos seus 70 anos, foram criados vários centros e órgãos de apoio às atividades de ensino, pesquisa e extensão. Entre eles, destacam-se o já mencionado LAPEX, o Centro Olímpico, o Centro de Excelência Esportiva (CENESP), o Centro de Memória do Esporte (CEME), o Centro de Lazer e Recreação do Idoso (CELARI), o Centro de Desenvolvimento do Esporte Recreativo e do Lazer (CEDES) e o Centro de Estudos Olímpicos (CEO).

$\mathrm{Na}$ área da divulgação científica, a ESEF publica, desde 1994, a Revista Movimento, um importante periódico que aborda temas relacionados à educação física, ao esporte, ao lazer e às atividades físicas na perspectiva das ciências humanas e sociais. Em anos recentes, a revista passou a ser disponibilizado também de forma eletrônica em português, inglês e espanhol, com acesso livre à comunidade acadêmica nacional e internacional.

Desde sua criação, a ESEF tem estabelecido contato e realizado parcerias com universidades e centros de pesquisa do Brasil e do exterior, com o intuito de trocar experiências e conhecimentos e, com isso, enriquecer a formação dos seus professores, estudantes e pessoal técnico.

Nas últimas décadas, as demandas de uma sociedade globalizada e em permanente mudança, o rápido desenvolvimento científico e tecnológico, a mobilidade de pessoas para trabalhar e estudar em outros países, entre outros fatores, vêm exigindo das universidades uma postura mais incisiva, cujas repercussões e impactos estejam além das questões locais. A internacionalização da educação superior se tornou uma realidade e muitas universidades vêm desenvolvendo esforços nessa direção, entre elas, a UFRGS. 
Como parte integrante desse processo, a ESEF defronta-se hoje com a necessidade de refletir sobre a sua trajetória e de pensar caminhos para a internacionalização dos seus programas e atividades, seja no ensino, na pesquisa ou na extensão.

Este estudo teve por objetivo descrever o caminho seguido pela ESEF-UFRGS em direção à internacionalização e destacar alguns dos desafios para sua efetivação. A pesquisa tomou como referência depoimentos de docentes disponíveis no CEME, registros das atividades dos pesquisadores e dos grupos de pesquisa junto à Base de Dados do CNPq, publicações científicas e documentos sobre a trajetória da instituição. $\mathrm{O}$ estudo levou em consideração o período que se estende do início dos anos de 1970 até os dias atuais.

O ensaio está organizado em duas partes. A primeira apresenta um panorama geral da internacionalização da educação superior, destacando algumas das suas características mais marcantes; enquanto a segunda aborda a trajetória da ESEF em direção à internacionalização, tendo como foco as atividades de pesquisa e a mobilidade de estudantes de graduação.

\section{INTERNACIONALIZAÇÃo dA EdUCAÇÃo SuPERIOR}

A internacionalização da educação superior é um processo complexo e multifacetado, com importantes implicações econômicas, políticas, sociais e culturais para os países, as instituições e as pessoas envolvidas. Nas últimas décadas, dada sua importância, tornou-se um tema central na agenda de governos, de organismos internacionais, de setores empresariais e de instituições universitárias, para mencionar apenas os principais agentes envolvidos no processo.

Os governos, sejam de nações desenvolvidas ou em desenvolvimento, reconhecem, cada vez mais, a necessidade de incluir a internacionalização da educação superior em políticas de educação, de ciência e tecnologia e de relações internacionais, uma vez que a identificam como uma força essencial para o desenvolvimento dos países em um mundo globalizado. 
Os organismos internacionais, como a Organização das Nações Unidas para a Educação, a Ciência e a Cultura (UNESCO), o Banco Mundial, a Organização Mundial do Comércio (WTO) e a Organização para Cooperação e Desenvolvimento Econômico (OECD) criaram grupos de trabalho, organizaram encontros e produziram documentos sobre o assunto. Tal esforço evidencia a importância da internacionalização da educação superior para as relações políticas e comerciais entre os países ${ }^{1}$.

Os setores empresariais, em decorrência dos acordos internacionais (GATS) $)^{2}$, que incluíram a educação superior na lista de serviços a serem comercializados entre os países, examinam as oportunidades de negócios colocados pela internacionalização da educação superior. A oferta de cursos de graduação e pós-graduação em outros países e a mobilidade de docentes e estudantes através das fronteiras por razões comerciais e com fins lucrativos é uma realidade hoje facilmente identificável.

As instituições de educação superior consideram o assunto de fundamental importância para a realização de sua missão de formar e qualificar pessoas, de produzir conhecimento e de gerar tecnologia. Em todo o mundo estabelecem-se acordos de cooperação entre universidades de diferentes países. Associações de universidades foram e continuam a ser criadas em todas as regiões do planeta, com o propósito de fomentar a cooperação internacional. Gestores, professores e estudantes, entre outros segmentos da educação superior, estão atentos às possibilidades e aos desafios colocados pela internacionalização.

\footnotetext{
'Vários documentos e estudos foram elaborados por esses organismos internacionais, entre eles destacamos: UNESCO, 2004; WIT, Hans de; JARAMILLO, Isabel Christina; GACELÁVILA, Jocelyne; KNIGHT, Jane (eds.) Higher Education in Latin America: the international dimension. Washington: The World Bank, 2005; OECD. Internationalisation and trade in higher education: opportunities and challenges. Paris, 2004.

${ }^{2} \mathrm{O}$ GATS (General Agreement on Trade in Services) é um acordo internacional sobre comércio de serviços administrado pela Organização Mundial do Comércio (WTO). Trata-se do primeiro acordo multilateral a cobrir o comércio de serviços. Os acordos internacionais prévios tratavam do comércio de produtos. O GATS definiu a educação como um dos doze serviços primários, sendo a educação superior um dos cinco subsetores da educação.
} 
Em termos de educação superior, vivemos num tempo em que as possibilidades são muitas e as ofertas diversificadas. Um número crescente de estudantes viaja para o exterior a fim de realizar estudos de graduação e pós-graduação; outros se engajam em cursos oferecidos por instituições estrangeiras em seus próprios países. Outros ainda matriculam-se em instituições do exterior e realizam cursos em seus próprios países, fazendo uso da internet diretamente de suas casas, do trabalho ou de locais especialmente oferecidos para esse fim.

Da mesma forma, pesquisadores e docentes se deslocam de um país para outro com o propósito de desenvolverem projetos de investigação com colegas de instituições estrangeiras e atuarem em programas de graduação e pós-graduação. Projetos de pesquisa e programas de ensino internacionais, envolvendo universidades de diferentes países, estão em andamento, inclusive no Brasil.

A internacionalização da educação superior é consequência da crescente interdependência dos países. Trata-se assim de um processo com dimensões locais e globais, com valores e interesses que convergem ou divergem, conforme o contexto e os agentes envolvidos. As oportunidades e os desafios dependem de vários fatores; e os benefícios e prejuízos são de diferentes tipos e magnitudes.

Assim, a internacionalização da educação superior apresenta diferentes dimensões, não necessariamente excludentes, entre elas: (a) as atividades de cunho internacional que contemplam: mobilidade de docentes e discentes; relações, parcerias e projetos; programas acadêmicos de graduação, mestrado e doutorado; e iniciativas de pesquisa; (b) o provimento de educação superior para outros países por meio de novos arranjos (extensão de campus, franquias e educação à distância); (c) a inclusão de uma dimensão intercultural ou global no currículo e no processo de ensino/aprendizagem; (d) o desenvolvimento de projetos internacionais, com ênfase na educação superior como negócio (KNIGHT, 2005; 2004). 
Esse estudo focaliza o caminho seguido pela ESEF-UFRGS na direção da internacionalização no sentido apresentado no item (a), acima referido. Entretanto, por razões de espaço, a abordagem está restrita a duas atividades de cunho internacional ali mencionadas: atividades de pesquisa e à mobilidade de estudantes de graduação.

\section{Internacionalização da Pesquisa na ESEF}

A internacionalização da pesquisa na ESEF teve início com a inauguração do LAPEX, em $1972^{3}$. A instalação do Laboratório fez parte de uma política nacional voltada para o desenvolvimento do esporte de alto rendimento no Brasil. Um dos problemas do esporte nacional identificados pelas autoridades governamentais da época dizia respeito aos inexpressivos resultados dos atletas e das equipes brasileiras em competições internacionais. Esses se deviam, em grande medida, à falta de amparo científico ao esporte praticado no país. A conquista do tricampeonato mundial de futebol no México, em 1970, colocou em evidência não apenas o talento dos jogadores brasileiros, mas o treinamento físico com base científica realizado pela comissão técnica da seleção ${ }^{4}$. A vitória brasileira contribuiu de maneira decisiva para que a Medicina do Esporte, a Fisiologia do Exercício, a Cineantopometria, entre outras especialidades científicas, fossem reconhecidas como necessárias para impulsionar o esporte nacional.

O Diagnóstico da Educação Física/Desportos do Brasil, publicado em 1971, apresentou os resultados de dois anos de levantamentos sobre a situação do setor no país. O documento evidenciou um quadro negativo em termos de desenvolvimento científico.

\footnotetext{
${ }^{3}$ O LAPEX foi inaugurado em agosto de 1972. No ano seguinte, a UFRGS firmou convênio com - Departamento de Educação Física e Desportos do Ministério da Educação e Cultura, sendo - LAPEX oficialmente implantado com um anexo da ESEF. Para uma análise detalhada da criação do LAPEX, ver: MAZO, 2000, p. 11-22.

${ }^{4}$ Para mais sobre as bases científicas do treinamento físico dos atletas brasileiros para a Copa de 70 no México, consultar: GONÇALVES, 2004.
} 
As Escolas Superiores de Educação Física/ Desportos ainda não se adequaram efetivamente para as imposições da Medicina Desportiva, não realizam pesquisas e não possuem formas rotineiras de intercâmbio. (COSTA, 1971, p. 356)

Com o propósito de promover uma transformação nesse quadro, foram planejados laboratórios de pesquisa a serem instalados em Escolas de Educação Física de diferentes estados brasileiros. O LAPEX foi um deles. Seu foco inicial estava na transferência de tecnologia e no desenvolvimento de pesquisas, em especial nas áreas da Cineantropometria e da Fisiologia do Exercício. De acordo com Eduardo Henrique de Rose, idealizador e responsável pela criação do LAPEX:

A função do projeto [Projeto Brasil] ${ }^{5}$ era transferência de tecnologia, quer dizer, numa área que não havia nenhuma tecnologia, como é que se avalia um atleta; como é que se prescreve um treinamento; como é que se faz ciência do esporte. A tecnologia era zero, então nossa função era transferência de tecnologia; era criar centros no Brasil e profissionais brasileiros capazes de apoiar o esporte de alto rendimento, que era a prioridade do Governo. (Entrevista concedida a Janice Zarpellon Mazo, em 21/08/1997)

De Rose foi um dos precursores das ações de internacionalização da ESEF junto aos pesquisadores de universidades alemãs e norte-americanas. Em 1971, ele realizou estágio em ergoespirométrica no laboratório do Professor Wildor Hollmann, um dos pioneiros nessa área de investigação, na Universidade de Esportes de Colônia (Deutsche Sporthochschule Koln), na Alemanha. Esse contato permitiu que, quando da implantação do LAPEX, o Professor Hollmann viesse ao Brasil para auxiliar os pesquisadores locais no desenvolvimento de projetos de pesquisa na área de avaliação funcional. Essa colaboração continuou

${ }^{5}$ O Projeto Brasil foi desenvolvido com apoio do DED-MEC de 1976 a 1982. Para uma visão geral do Projeto, consultar: ROCHA, Maurício et al. Fisiologia do exercício. In: COSTA, Lamartine (org.) Atlas do esporte no Brasil. Rio de Janeiro: Shape, 2005. p. 657-659. 
em período posterior com a vinda de pesquisadores alemães, como foi o caso do Professor Ulf Georg Klemt, em 1975, e com visitas e estágios de treinamento de pesquisadores do LAPEX na Alemanha ${ }^{6}$.

As ações de internacionalização junto a centros de pesquisa dos Estados Unidos tiveram início em 1973, quando Eduardo Henrique De Rose, agora na condição de coordenador do LAPEX, realizou visita ao país com o intuito de buscar referências para os trabalhos a serem desenvolvidos na ESEF. Posteriormente, outros membros da equipe visitaram laboratórios na Pensilvânia e no Texas, nesse último para conhecer o trabalho realizado por Kenneth Cooper ${ }^{7}$.

Nos anos seguintes, essas ações se ampliaram para outros países da Europa, quando a equipe técnica do LAPEX, composta por profissionais de medicina e educação física, visitou e realizou estágios de curta duração em laboratórios de pesquisa em Roma (Itália), Estocolmo (Suécia), Jyvaskyla (Finlândia), Louvain (Bélgica) e Paris $(\text { França })^{8}$. (MAZO, 2000, p.13)

Nos primeiros anos, o objetivo principal da colaboração entre os pesquisadores do LAPEX e os pesquisadores europeus e norteamericanos era adquirir conhecimento e qualificar pessoal para a implantação do Laboratório e para o desenvolvimento de projetos de pesquisa.

De Rose descreve o caminho seguido nesse período inicial:

Nós buscávamos os melhores professores do mundo, os melhores centros do mundo: as nossas pessoas iam para lá, estagiavam e voltavam para aplicar aqui. (Entrevista concedida a Janice Zarpellon Mazo, em 21/08/1997).

\footnotetext{
${ }^{6}$ Existem registros da passagem de quatro pesquisadores da equipe do LAPEX pela Universidade de Esportes de Colônia: Belmar José Ferreira de Andrade (médico), Jorge Pinto Ribeiro (médico), Antônio Carlos Stringhini Guimarães (educador físico) e Ricardo Demétrio de Souza Petersen (educador físico).

${ }^{7}$ Nesse período, dois pesquisadores da LAPEX estiveram na Universidade da Pensilvânia e no centro de pesquisa de Kenneth Cooper, no Texas: Antônio Carlos Stringhini Guimarães e Ricardo Demétrio de Souza Petersen.

${ }^{8}$ Para o período de 1972 a 1977, existem registros de visitas e/ou estágios em laboratórios e centros de pesquisa europeus, dos seguintes membros do LAPEX: Benno Becker (Roma), Jorge Pinto Ribeiro (Roma, Estocolmo e Jyvaskyla); Antônio Carlos Stringhini Guimarães (Roma, Louvain, Paris); e Ricardo Demétrio de Souza Petersen (Roma, Louvain, Paris).
} 
Nesse período, o LAPEX trouxe também pesquisadores norteamericanos e alemães para ministrar cursos e palestras e, em alguns casos, assessorar as pesquisas em andamento, entre eles estavam: Kenneth Cooper, Michel Pollock, Bruno Balke, Peter Cavanagh, John Edward Linday Carter, Richard Host, Wilmor Hollmann todos especialistas de reconhecido prestígio internacional. (MAZO, 2000, p. 13)

Em 1975, ainda nos primeiros anos de funcionamento, o LAPEX passou a receber médicos de países da América Latina e mesmo da Europa, que procuravam o Laboratório com o intuito de realizar estágios de capacitação. Iniciou-se assim um período de intensa atividade internacional. Entre 1975 e 1981, os relatórios registram 15 médicos de 8 países (Equador, México, Venezuela, Argentina, Colômbia, República Dominicana, Nicarágua e Espanha) realizando estágio no LAPEX.

Desta forma, ao mesmo tempo em que o LAPEX mantinha cooperação com países da Europa e da América do Norte para qualificar seu quadro de pesquisadores, treinava pessoal de vários países da América Latina, na sua quase totalidade médicos, para atuar na área da Medicina do Esporte e da avaliação funcional.

Os pesquisadores do LAPEX passaram também a viajar para o exterior a fim de treinar pessoal e dar apoio técnico para a instalação de laboratórios em países da América Latina. Segundo De Rose:

Também começamos a dar apoio ao Ministério da Educação no treinamento de outros países; então o LAPEX foi para o Equador, para a Bolívia, Argentina, Uruguai, Paraguai, Colômbia, montando pequenos LAPEX através de programas do Governo Brasileiro e treinando o pessoal de lá. (Entrevista concedida a Janice Zarpellon Mazo, em 21/08/1997) 
Uma característica importante do período é que houve um forte impacto da pesquisa científica realizada em outros países nas pesquisas desenvolvidas no LAPEX. Os pesquisadores procuravam transpor para o contexto brasileiro as pesquisas realizadas em países considerados mais avançados. Os estudos se centravam na cientropometria e na fisiologia do esforço. Belmar José Ferreira de Andrade, coordenador do LAPEX no período de 1980 a 1986 e membro da equipe técnica desde 1972, descreve o tipo de pesquisa realizada na época:

[...] a fisiologia do exercício, o treinamento físico como uma especialidade definida eram coisas muito novas: isso tudo não existia no currículo das faculdades nem de Educação Física, nem de Medicina. Era uma coisa nova, e nós estávamos 'pescando' tudo que estava ocorrendo no mundo e repetindo aqui: era uma pesquisa de confirmar dados de pesquisa de outros centros, de confirmar resultados de outras populações, ver se eles se reproduziam na nossa população, treinar tecnologia e treinar técnica [...] (Entrevista concedida a Janice Zarpellon Mazo, em 23/04/1997).

As pesquisas realizadas no LAPEX nesse período não tiveram impacto apenas local, influenciaram também os rumos da pesquisa brasileira e de países latino-americanos. O Laboratório atuava como intermediário na transferência de tecnologia entre países mais e menos desenvolvidos do que o Brasil na área das ciências do esporte e do exercício.

As atividades de internacionalização promovidas pelo LAPEX trouxeram contribuições importantes para o curso de graduação em Educação Física da ESEF. Os contatos com pesquisadores estrangeiros que visitavam e ministravam cursos no Laboratório criaram oportunidades e promoveram estímulos para os estudantes de Educação Física que atuavam com estagiários. Vários estudantes da ESEF, participantes do grupo inicial de estagiários do LAPEX, 
deram sequência a sua formação científica realizando mestrado e doutorado no exterior ${ }^{9}$. Esses contatos promoveram também uma mudança no perfil de ensino da ESEF, na época pouco orientado para os avanços científicos, exigindo melhor formação e atualização permanente dos professores.

Além disso, os conhecimentos e as experiências adquiridas com especialistas de outros países tiveram repercussão no meio esportivo. Com o objetivo de apoiar o desenvolvimento do esporte nacional, a equipe do LAPEX realizou avaliações de atletas nos Jogos PanAmericanos do México, nos Jogos Escolares Brasileiros (JEBs) e no campeonato brasileiro de futebol.

Entre 1985 e 1990, o LAPEX experimentou um segundo momento de intensa atividade internacional. No período, 19 médicos provenientes de diferentes países da América Latina e 26 da Espanha, atuaram como estagiários no Laboratório. Esses profissionais não apenas adquiriam conhecimento e experiência que depois levavam para os seus países, mas contribuíam para o desenvolvimento das atividades de pesquisa do Laboratório.

$\mathrm{Na}$ área dos serviços à comunidade, em especial na parte de testes ergométricos, os estagiários estrangeiros foram integrados às atividades do Laboratório, sendo responsáveis por uma parcela considerável dos trabalhos de avaliação. Em certa medida, pode-se afirmar que a internacionalização da pesquisa promovida pelo LAPEX trouxe também benefícios aos projetos de extensão da ESEF.

Com a inauguração das novas instalações do LAPEX, ocorrida em 1997, a ESEF passou a oferecer condições mais favoráveis para a pesquisa em várias áreas, com espaço físico, equipamentos e pesquisadores qualificados. Essas condições, somadas ao apoio dos

\footnotetext{
${ }^{9}$ No final da década de 1970 e início dos anos de 1980, três estudantes de Educação Física e um de Medicina, do grupo inicial de estagiários do LAPEX, realizaram mestrado e doutorado nos Estados Unidos: Jorge Pinto Ribeiro (Doutorado em Fisiologia do Exercício, Universidade de Boston); Antônio Carlos Stringhini Guimarães (Mestrado em Biomecânica, Universidade de lowa); Ricardo Demétrio de Souza Petersen (Mestrado em Aprendizagem Motora, Universidade de lowa; e Doutorado em Desenvolvimento Motor, Universidade de Maryland); Newton Fernando Fortuna (Mestrado em Aprendizagem Motora, Universidade de lowa).
} 
órgãos governamentais de fomento à pesquisa, permitiram uma ampliação substancial no número de publicações em revistas internacionais. Além disso, continuaram acontecendo as visitas, os cursos e as palestras de pesquisadores de renome internacional. Da mesma forma, pesquisadores do Laboratório visitaram instituições estrangeiras, proferiram palestras no exterior e participaram de eventos científicos internacionais.

As ações de internacionalização da ESEF na área da pesquisa, entretanto, evidenciam dificuldades que merecem ser destacadas, sendo a principal delas a quase inexistência de projetos em colaboração com instituições estrangeiras. Na parte que segue, indicamos alguns dos motivos que talvez contribuam para tal situação.

Os docentes que realizam seus programas de doutorado (pleno ou parcial) no exterior, após o retorno ao Brasil, concentram-se, inicialmente, em se estabelecer como pesquisadores na própria instituição, buscando na ESEF, na UFRGS e nos órgãos governamentais de fomento os recursos e as condições para o desenvolvimento de suas pesquisas. Os esforços em nível local, embora necessários e desejáveis, necessitam ser equilibrados com os esforços em nível internacional, uma vez que as parcerias com pesquisadores de outros países são também uma forma de alavancar a pesquisa local.

Por outro lado, a falta de condições locais apropriadas para a pesquisa é um fator inibidor para o estabelecimento de parcerias internacionais, pelo menos com países considerados mais ricos e avançados em termos tecnológicos. Isso é assim uma vez que pesquisas em áreas como biomecânica e fisiologia, por exemplo, requerem equipamentos cuja aquisição e manutenção tem custos elevados. Para os pesquisadores desses países não há benefícios nesse tipo de parceria, uma vez que dependem deles os recursos para o desenvolvimento dos projetos de pesquisa em colaboração com os pesquisadores brasileiros. Entretanto, para os pesquisadores brasileiros, uma vez estabelecida a parceria, os benefícios são muitos, desde o envio de estudantes de pós-graduação para a realização de parte de sua formação no exterior, passando pela concretização de 
projetos de pesquisa com equipamentos e tecnologia de ponta, e chegando à produção científica de nível internacional. Em outras palavras, projetos de colaboração internacional em algumas áreas representam uma oportunidade para alavancar o desenvolvimento científico de grupos de pesquisa na ESEF. Dessa forma, a melhoria continuada dos equipamentos, das instalações e do quadro de pesquisadores é condição necessária para o desenvolvimento de projetos em cooperação internacional. Nesse sentido, ainda são poucos os projetos da ESEF que obtêm sucesso na busca de recursos para a melhoria das condições de pesquisa do LAPEX.

Em algumas áreas, contudo, as parcerias entre pesquisadores da ESEF e de universidades de outros países é plenamente possível. As pesquisas em crescimento e desenvolvimento somatomotor, por exemplo, têm caminhado cada vez mais na direção de investigar os aspectos socioculturais relacionados a variáveis como força, flexibilidade, índice de massa corporal, etc. Existe nessa área a possibilidade de projetos de cooperação internacional, cuja viabilidade depende de esforços conjuntos e cujos resultados interessam às partes envolvidas. Encontramos a mesma situação em áreas de pesquisa em que a tecnologia não desempenha um papel tão importante. Algumas pesquisas em história, antropologia e pedagogia com foco no esporte, no lazer, na dança, nas atividades físicas, etc., para mencionar apenas algumas das áreas em que a ESEF tem tradição estabelecida, poderiam ser realizadas em parceira com universidades de outros países, havendo benefícios mútuos. As possibilidades de trabalho conjunto sobre temas de interesse comum, com países latino-americanos, em particular os mais próximos geográfica e culturalmente; com os países africanos de língua portuguesa; e com Portugal, principalmente pelas relações acadêmicas já estabelecidas, parecem promissoras.

Outro ponto digno de nota, diz respeito à necessidade de estabelecer, ao longo dos estudos de doutoramento no exterior, vínculos de pesquisa mais sólidos com a instituição receptora e, além disso, realizar esforços para preservar esses vínculos após o retorno ao Brasil. Isso é fundamental para a internacionalização das ações 
de pesquisa da ESEF, uma vez que a formação no exterior não é somente uma maneira de qualificar quadros, obtendo conhecimentos e experiências em áreas específicas de pesquisa, mas também uma oportunidade de estabelecer parcerias científicas duradouras. No caso da ESEF, foram poucas as situações em que isso ocorreu. $\mathrm{Na}$ maioria das ocasiões, não foram estabelecidos e/ou mantidos projetos de pesquisa em cooperação com as instituições onde os professores realizaram seus doutoramentos.

Por fim, é importante destacar que internacionalização das atividades de pesquisa por meio de parcerias com instituições de outros países traz contribuições relevantes não apenas para a produção do conhecimento, mas também para a formação de jovens pesquisadores. A experiência da ESEF nessa área, embora reduzida, demonstra que ações bem sucedidas geram boas possibilidades para os estudantes.

\section{INTERNACIONALIZAÇÃo da GraduaÇão na ESEF}

A internacionalização do programa de graduação teve início com o convênio firmado entre a ESEF e a Universidade de Esportes de Colônia, na segunda metade da década de 1980. Entre 1988 e 1992, vários estudantes de graduação da ESEF realizaram estudos naquela universidade. $\mathrm{O}$ caminho inverso não aconteceu; apenas um estudante alemão esteve na ESEF. Após esse período, o convênio não foi renovado e as possibilidades de intercâmbio cessaram.

No final dos anos de 1990, a ESEF firma convênio de cooperação com a Universidade do Porto, dando início a uma parceria mais duradoura. Vários estudantes brasileiros e portugueses participaram do intercâmbio. As condições oferecidas pela universidade portuguesa eram bastante favoráveis aos estudantes brasileiros. No caso da ESEF, a falta de recursos específicos para o convênio e a ausência de uma política institucional criava muitas dificuldades para os estudantes portugueses.

Nos anos que se seguiram, a UFRGS criou mecanismos para facilitar a internacionalização da graduação. Normas foram criadas 
para o reconhecimento dos estudos realizados no exterior. Entretanto, a mobilidade internacional no âmbito dos cursos de graduação em Educação Física da ESEF configura-se, ainda, numa prática restrita. Diferentemente do contexto europeu, onde o Programa Erasmus e o Processo de Bolonha da União Européia incentivam a mobilidade discente, no contexto universitário brasileiro os esforços políticos estão mais concentrados nas questões de democratização do acesso e de assistência estudantil, aos programas de ações afirmativas e inclusão social. (BASTOS, 2007).

$\mathrm{Na}$ atualidade, os estudantes da ESEF têm a possibilidade de concorrer em programas de mobilidade internacional com bolsas de estudo (Associação de Universidades do Grupo Montevideo AUGM; Universidad Autónoma de Madrid, Espanha; diversas Universidades Portuguesas, através do Programa Santander LusoBrasileiras; diversas universidades européias, através do Programa Erasmus Mundus; e Universidade de Tübingen, Alemanha) e sem bolsas de estudo (Universidade do Texas/Austin, nos Estados Unidos; Universidade do Québec, Canadá; Universidade do Porto, Portugal; Universidade de Grenoble, França; Humboldt Universität Zu Berlin e Ruprecht-Karls Universität Heidelberg, Alemanha).

De forma geral os intercâmbios internacionais possibilitam que os estudantes realizem seus Planos de Estudos durante um semestre, com possibilidade de ampliação para mais um semestre. Aquantidade de bolsas oferecidas também varia de acordo com os períodos e instituições participantes.

Dentre as opções disponíveis, os programas mais procurados pelos estudantes dos cursos de graduação em Educação Física são aqueles que disponibilizam bolsas de estudo tendo em vista o custo financeiro que envolve sua permanência no exterior. E, dentre estes, a preferência se dá para estudos da Universidade do Porto, instituição onde diversos docentes da ESEF realizaram seu doutoramento, e no Programa da AUGM, pela proximidade geográfica. Na primeira edição, nove estudantes de graduação realizaram mobilidade internacional, sendo que seis deles realizaram seus estudos na 
Universidade do Porto e uma estudante na Universidade Técnica de Lisboa. Para a segunda edição, dois estudantes do curso de Licenciatura em Educação Física já foram selecionados no Programa ESCALA/AUGM.

Uma das iniciativas mais inovadoras de intercâmbio internacional para alunos de graduação é o Programa de Licenciaturas Internacionais (PLI). Tal programa constitui-se numa iniciativa da CAPES e da Universidade de Coimbra/Portugal, com o apoio do Grupo Coimbra de Universidades Brasileiras, e visa elevar a qualidade de cursos de formação inicial de professores nas seguintes áreas: Química, Física, Matemática, Biologia, Português e Educação Física. Através de edital (035/2010 - CAPES), diversas instituições de ensino superior do Brasil tiveram oportunidade de enviar seus projetos para participar desse Programa que, além de destinar-se exclusivamente aos alunos de cursos de Licenciatura (modalidade de formação geralmente pouco privilegiada em intercâmbios internacionais em relação a outras áreas de formação), apresenta outros três diferenciais. Um deles é a dupla titulação: o estudante que cumprir integralmente o plano de estudos irá obter o diploma do Primeiro Ciclo da Universidade de Coimbra e o diploma de Licenciatura da Instituição Brasileira. Outro é o direcionamento para alunos oriundos de escolas públicas: para participar do referido Programa o estudante deveria ter cursado todo o Ensino Médio e pelo menos dois anos do Ensino Fundamental em escolas públicas brasileiras. E, além dos estudantes receberem bolsas de estudos durante os vinte e quatro meses que permanecerem na Universidade de Coimbra, estão previstas a realização de quatro missões de trabalho: deslocamento de um professor de cada Instituição Brasileira participante do Programa para acompanhamento da integração dos estudantes brasileiros à Universidade de Coimbra e do desenvolvimento das atividades propostas.

No âmbito da UFRGS participam do PLI sete estudantes, sendo quatro do curso de Licenciatura em Educação Física. Tais estudantes ainda não tinham vivenciado a experiência de morar longe de suas famílias, bem como nunca haviam viajado para o exterior. A 
experiência de estudar na Universidade de Coimbra tem sido para eles até o momento enriquecedora. Além da experiência de vida, estão ampliando seus conhecimentos no âmbito da Cultura do Movimento Humano e tendo a oportunidade de estabelecer relações com estudantes de diversos países tendo em vista que a Universidade de Coimbra desenvolve diversos programas de intercâmbios internacionais.

Talvez os fatores mais limitantes para o aumento da mobilidade internacional no âmbito dos cursos de graduação sejam o domínio da língua inglesa e a disponibilidade de bolsas de estudo. De acordo com Charle et al. (2004) a barreira do domínio de uma língua estrangeira é menos forte para estudantes oriundos de classes sociais abastadas, porém a barreira financeira continua decisiva uma vez que os custos financeiros para se viver por um ano ou quase isso, no exterior, são altos. Lima e Maranhão (2009) também afirmam que, devido aos altos custos requeridos, a educação internacional ainda é uma experiência acessível a poucos. Azevedo (2007) destaca, ainda, que se tornam atores no cenário de mobilidade internacional aqueles estudantes que estão integrados a grupos de pesquisa internacionais: não basta, portanto, dominar uma língua estrangeira, é preciso produzir academicamente. Neste sentido a realização de projetos de pesquisa em cooperação com Universidades no exterior talvez possam ser idealizados de forma a envolver também estudantes de graduação, ampliando, dessa forma, as possibilidades de mobilidade internacionais.

\section{Considerações Finals}

A ESEF vem desenvolvendo, desde a década de 1970, iniciativas em direção à internacionalização da pesquisa. As experiências mais significativas da Instituição no âmbito da colaboração internacional ocorreram nessa área. O LAPEX tem desempenhado um papel fundamental nesse sentido. Em 40 anos, promoveu visitas e estágios de pesquisadores da ESEF a instituiçõos de diversos países. Da mesma forma, promoveu visitas, palestras e cursos de pesquisadores 
estrangeiros na ESEF. Por mais de uma década, ofereceu estágios para profissionais de diferentes países da América Latina. Nos últimos anos, os pesquisadores da ESEF ampliaram de maneira substancial o número de publicações em periódicos internacionais e participaram de eventos científicos em vários países. Além disso, vem desenvolvendo, embora em pequeno número, projetos de pesquisa com universidades estrangeiras de reconhecido prestígio internacional.

Em relação à mobilidade de estudantes de graduação, a experiência da ESEF é ainda recente. Até o momento, algumas parcerias e projetos funcionaram de maneira satisfatória; enquanto outros mostraram claras deficiências. Para os estudantes brasileiros, os principais obstáculos estão no domínio de língua estrangeira e, para aqueles que não obtêm apoio financeiro, nos recursos para financiar a estada no exterior. Os estudantes estrangeiros também encontram dificuldades quando realizam estudos na ESEF, em especial pela falta de moradia estudantil.

Em que pesem os esforços institucionais e os resultados positivos já atingidos, há pontos que necessitam ser melhorados tanto na pesquisa quanto na mobilidade de estudantes. $\mathrm{O}$ maior desafio, entretanto, é instalar uma cultura de internacionalização em que a relação com instituiçõos de educação superior de outros países seja vista como qualificadora das atividades de ensino e pesquisa. 
The Faculty of Physical Education of the Federal University of Rio Grande do Sul and the internationalization of higher education

Abstract: In this study, we attempted to establish the path of ESEF-UFRGS in direction to the internationalization of higher education and to highlight the main challenges to its realization. The study took as reference staff interviews, institutional documents, research reports and scientific publications. The results pointed out that ESEF-UFRGS has taken action in direction of the internationalization of its research activities and undergraduate program. The main actions were student and academic mobility, international publications and participation in scientific meetings with and without presentations. The major challenge has been to establish a culture of internalization in which the exchange with institutions of other countries is seen by the academic community as way to qualify teaching and research.

Keywords: Physical Education. History. Higher Education

\begin{abstract}
La Faculdad de Educación Física de la Universidad Federal del Rio Grande del Sur y la internacionalización de la educación superior Resumen: En este estudio, hemos tratado de establecer la trayectoria de la ESEF-UFRGS en dirección a la internacionalización de la educación superior y destacar los principales desafíos para su realización. El estudio tomó como referencia entrevistas con los docentes, documentos institucionales, informes de investigación y publicaciones científicas. Los resultados señalaron que la ESEF-UFRGS se ha tomado medidas en la dirección de la internacionalización de sus actividades. Las principales acciones fueron la movilidad estudiantil y académica, publicaciones en revistas internacionales y participación en eventos con y sin presentación de trabajos. El mayor desafío ha sido establecer una cultura de internalización en la cual el intercambio con las instituciones de otros países es considerado por la comunidad académica como manera de calificar la enseñanza y la investigación. Palabras clave: Educación Física. Historia. Educación Superior.
\end{abstract}




\section{REFERÊNCIAS}

AZEVEDO, Mário Luiz Neves de. A integração dos sistemas de educação superior na Europa: de Roma a Bolonha ou da integração econômica à integração acadêmica. Educação Temática Digital, Campinas, v. 9, n.esp., p.133-149, dez 2007. Disponível em <http://www.fae.unicamp.br>. Acesso em: 19 fev. 2011.

BASTOS, Carmem Célia Barradas Correia. O Processo de Bolonha no espaço europeu e a reforma universitária brasileira. Educação Temática Digital, Campinas, v. 9, n.esp., p.95-106, dez 2007. Disponível em: <http://www.fae.unicamp.br>>. Acesso em: 19 fev. 2011.

CHARLE, Christophe et. al. Ensino superior: o momento crítico. Educação e Sociedade, Porto Alegre, v. 25, n.88, p. 961-975, Especial-out 2004. Disponível em: <http://www.scielo.br>. Acesso em: 18 mar 2011

COSTA, Lamartine Pereira. Diagnóstico de educação física/desportos no Brasil. Rio de Janeiro, Ministério da Educação e Cultura: 1971. p. 43-47.

GONÇALVES, Antonio Jorge et al. O "futebol arte" e o "planejamento México" na copa de 70: as memórias de Lamartine Pereira da Costa. Movimento, Porto Alegre, v. 10, n. 3, p. 113-130, 2004.

KNIGHT, Jane. Internationalization remodeled: definition, approaches, and rationales. Journal of Studies in International Education, Bethesda, v. 8. n.1, p. 5-31, 2004.

KNIGHT, Jane. An internationalization model: responding to new realities and challenges. In: WIT, Hans de; et al (ed.) Higher Education in Latin America: the international dimension. Washington: The World Bank, 2005. p. 1-38.

LAUS, Sonia Pereira; MOROSINI, Marília Costa. Internationalization of higher education in Brazil. In: WIT, Hans de; et al (ed.) Higher Education in Latin America: the international dimension. The World Bank: Washington, 2005. p. 111-147.

LIMA, Manolita Correia; MARANHÃO, Carolina Machado Saraiva de Albuquerque. O sistema de educação superior mundial: entre a internacionalização ativa e passiva. Avaliação, Campinas, v. 14, n. 3, nov. 2009, p. 583-610. Disponível em: <http:// www.scielo.br> Acesso em: 19 mar. 2011.

MAZO, Janice Zarpellon. A criação do Laboratório de Pesquisa do Exercício da Escola de Educação Física da UFRGS. Movimento, Porto Alegre, v. 6, n. esp., 2000.

MOVIMENTO, Porto Alegre, v. 6, n. esp., 2000.

OECD. Internationalisation of higher education. Paris, 2004. OECD Policy Brief. 
Internationalisation and trade in higher education: opportunities and challenges. Paris, 2004.

ROCHA, Maurício et al. Fisiologia do exercício. In: COSTA, Lamartine (Org.) Atlas do esporte no Brasil. Rio de Janeiro: Shape, 2005. p. 657-659.

UNESCO. Higher education in a globalized society: Paris, 2004.

Agradecimento

Agradecemos a Prof. a Janice Zarpellon Mazo por disponibilizar ao público os depoimentos dos diretores do LAPEX por ela entrevistados. Tal esforço, além de preservar a memória da ESEF, torna possível e mais fácil o trabalho de outros pesquisadores, entre eles, os autores desse estudo. 
